\title{
A CONSTRUÇÃO DA CIDADANIA DOS POVOS INDÍGENAS LATINO AMERICANOS A PARTIR DO PRINCÍPIO DA AUTODETERMINAÇÃO
}

\author{
RAQUEL COELHO DE FREITAS ${ }^{1}$
}

UFCE, BRASIL

THAYNARA ARARIPE ${ }^{2}$

UFCE, BRASIL

ADRIAN NAVÁEZ MONCAYO 3

UFCE, BRASIL

\begin{abstract}
RESUMO: Com a inclusão de instrumentos jurídicos de reconhecimento da diversidade cultural nas constituições de alguns países latino-americanos, investiga-se o princípio da autodeterminação como fundamento da construção de uma cidadania para os povos indígenas que os compreendam como sujeitos políticos atuantes e diversos. Para isso, utiliza-se a revisão bibliográfica juntamente com a análise legislativa para observar a estruturação conceitual histórica internacional do princípio da autodeterminação, além da compreensão do que seria um cidadão indigena plenamente capaz, ou seja, um cidadão que tenha suas especificidades culturais respeitadas e que tais diferenças não o dificulte ou o impeça de ser reconhecido na sociedade como sujeito político ativo. Conclui-se, portanto, que a mera garantia formal do princípio da autodeterminação, apesar do seu simbolismo, é insuficiente para a ingerência de um conceito de cidadania que seja capaz de transformar realidades que historicamente foram marginalizadas.
\end{abstract}

PALAVRAS-CHAVE: Princípio da autodeterminação. Cidadania indígena. Diversidade cultural.

\begin{abstract}
With the inclusion of legal instruments for the recognition of cultural diversity in the constitutions of some Latin American countries, the principle of self-determination is investigated as the basis for the construction of a citizenship for the indigenous peoples who understand them as active and diverse political subjects. For this, the bibliographical revision is used together with the legislative analysis to observe the international historical conceptual structuring of the principle of self-determination, besides the understanding of what would be a fully capable indigenous citizen, that is, a citizen who has his cultural specificities respected and that such differences do not hinder or prevent him from being recognized in society as an active political subject. It follows, therefore, that the mere formal guarantee of the principle of selfdetermination, despite its symbolism, is insufficient to interfere with a concept of citizenship that is capable of transforming realities that have historically been marginalized.
\end{abstract}

KEYWORDS: Principle of self-determination. Indigenous citizenship. Cultural diversity.

\footnotetext{
1 Professora associada da Faculdade de Direito da Universidade Federal do Ceará. E-mail: rclcesar@gmail.com

2 Mestre em Ordem Jurídica Constitucional (Universidade Federal Do Ceará, Brasil). E-mail: thaynaraararipe1@gmail.com

3 Mestre em Ordem Jurídica Constitucional (Universidade Federal Do Ceará, Brasil). E-mail: adriancho1616@hotmail.com
} 


\section{Introdução}

Diante da conjuntura de redemocratização dos países em contexto de ditadura militar, da ampliação da participação política e do recrudescimento das condições socioeconômicas, sujeitos sociais historicamente marginalizados reivindicaram voz para suas demandas, ganhando destaque os povos indígenas.

Dessa maneira, alguns países latino-americanos incluíram, a partir da década de 80 , em suas constituições, instrumentos jurídicos de reconhecimento da diversidade cultural, destacando-se o protagonismo indígena na luta por seus direitos com base em princípios como o da autodeterminação.

Este artigo é dividido em três momentos: em um primeiro, revisase o conteúdo histórico e conceitual do princípio da autodeterminação como um projeto político de origem internacional, no qual se entende a identidade cultural como um elemento determinante para os processos políticos que emergem do movimento indígena contemporâneo.

A construção do princípio da autodeterminação é proposta a partir dos estudos formulados pela Organização das Nações Unidas (ONU), Organização Internacional do Trabalho (OIT) e os instrumentos normativos que estas têm desenvolvido ao longo da história, assim como pelas reflexões debatidas por James Anaya.

Em seguida, o conceito de cidadania será problematizado a partir do movimento constitucional latino-americano, no qual cidadanias adormecidas ao longo da história ganharam voz. Investiga-se o que seria um cidadão indígena plenamente capaz, ou seja, um cidadão que tenha suas especificidades culturais respeitadas e que tais diferenças não o dificulte ou o impeça de ser reconhecido na sociedade como sujeito político ativo.

Por fim, observa-se o ponto de intersecção dos conceitos até aqui construídos - princípio da autodeterminação e cidadania - em uma esfera prática, ao questionar a eficácia de uma cidadania apenas formalmente garantida e que não reflita o direito à diferença fundamentado no princípio da autodeterminação.

Para a construção desses argumentos, utiliza-se a pesquisa bibliográfica com o auxílio da análise legislativa para observar a estruturação conceitual histórica internacional do princípio da autodeterminação, além da compreensão do que seria um cidadão indígena plenamente capaz.

\section{Autodeterminação: um projeto político de cunho internacional}

O constitucionalismo latino-americano tem sido um movimento que reivindica a heterogeneidade e a reinvenção das propostas e das lutas dos povos latinos. Nesse contexto, o conceito de autodeterminação que se deseja resgatar é o formulado pelo professor James Anaya, relator especial para a situação dos direitos e liberdades fundamentais dos povos 
Espaço Ameríndio

indígenas das Nações Unidas desde 2008, que determina tal conceito como um princípio fundamental dos direitos coletivos na esfera do movimento indígena internacional.

Conjunto de normas de direitos humanos dito
genericamente pelos povos, incluídos os povos
indígenas, e baseado na ideia de que todos os setores da
humanidade têm o mesmo direito a decidir seu próprio
destino. A autodeterminação dá lugar a formas de
reparação que rompem com os legados do imperialismo,
a discriminação, a superação da participação
democrática e a subjugação cultural. (ANAYA, 2005, p.
137). (Tradução nossa).

Assim, este princípio constitui uma ferramenta mediante a qual os povos, de maneira voluntária, determinam sua condição política e governam suas vidas na relação com as instituições vigentes, ou seja, o princípio preceitua que tais instituições até podem exercer poder sobre os seus territórios, desde que em condições de igualdade e prevalecendo a liberdade sob as concepções próprias dos mesmos.

Para a compreensão da autodeterminação no cenário Latinoamericano, é relevante considerar que, só a partir do ano de 1960, em resposta à ruptura da hegemonia da luta de classe, surge uma geração de indígenas decidida a lutar pelos seus direitos com o objetivo de ganhar ingerência na esfera do direito internacional. Para a consecução de tal fim, os indígenas consolidaram processos organizativos que iam surgindo de maneira progressiva, ou seja, primeiro no âmbito local e, posteriormente, fundamentariam a mobilização indígena no âmbito internacional (BENAVIDES VANEGAS, 2001, p. 123-175).

Esse novo cenário, caracterizou-se pela auto-representação indígena nas diferentes searas da conversação local e global. Convertendo-se os indígenas em participantes e atores desse diálogo.

Segundo Anaya (2005, p. 93), esse fato deu lugar à criação de uma nova identidade indígena que reivindicou as agendas políticas locais nas instâncias internacionais.

Dessa maneira, em meados da década de setenta, se convocaram novas conferências internacionais ${ }^{4}$, a partir das quais os povos indígenas indicaram as falências do modelo integracionista estabelecido nos anos anteriores e deram continuidade às conversações em prol de mudanças.

Convém mencionar a importância do Convênio 169 de 1989 da OIT que, em seu artigo 7, estabelece a capacidade dos Povos Indígenas de assumir o controle das suas próprias instituições e formas de vidas, assim como o seu desenvolvimento econômico, e de manter e fortalecer suas identidades, línguas e religiões dentro do Estado em que moram.

4 O Sistema das nações Unidas convocou: A Conferência Internacional de Organizações não governamentais sobre a Discriminação das Populações Indígenas na América de 1997, o Conselho Mundial de Povos Indígenas de 1980 e o Grupo de Trabalho sobre Populações Indígenas de 1982. Desses espaços surgiram alguns projetos de Declarações sobre direitos dos Povos Indígenas (tradução nossa) (ANAYA, 2009, p. 43). 


\begin{abstract}
Artigo 70
1. Os povos interessados deverão ter o direito de escolher suas próprias prioridades no que diz respeito ao processo de desenvolvimento, na medida em que ele afete as suas vidas, crenças, instituições e bem-estar espiritual, bem como as terras que ocupam ou utilizam de alguma forma, e de controlar, na medida do possível, o seu próprio desenvolvimento econômico, social e cultural. Além disso, esses povos deverão participar da formulação, aplicação e avaliação dos planos e programas de desenvolvimento nacional e regional suscetíveis de afetá-los diretamente.

2. A melhoria das condições de vida e de trabalho e do nível de saúde e educação dos povos interessados, com a sua participação e cooperação, deverá ser prioritária nos planos de desenvolvimento econômico global das regiões onde eles moram. Os projetos especiais de desenvolvimento para essas regiões também deverão ser elaborados de forma a promoverem essa melhoria.

3. Os governos deverão zelar para que, sempre que for possível, sejam efetuados estudos junto aos povos interessados com o objetivo de se avaliar a incidência social, espiritual e cultural e sobre o meio ambiente que as atividades de desenvolvimento, previstas, possam ter sobre esses povos. Os resultados desses estudos deverão ser considerados como critérios fundamentais para a execução das atividades mencionadas.

4. Os governos deverão adotar medidas em cooperação com os povos interessados para proteger e preservar o meio ambiente dos territórios que eles habitam.
\end{abstract}

O teor do Convênio tornou-se um forte catalisador para que, em 2007, a Assembleia Geral aprovasse a Declaração das Nações Unidas sobre os Direitos dos Povos Indígenas (DNUDPI). Tal Declaração, apesar de não contar com caráter vinculante pros Estados, é produto de duas décadas de acordos e diálogos interculturais entre o Estado e os povos indígenas enquanto interlocutores políticos.

A novidade do DNUDPI frente ao Convênio 169 foi estabelecimento do direito à livre determinação propriamente dito dos povos indígenas e, além disso, constitui o eixo dos outros direitos coletivos ali reconhecidos. Não obstante, com o objeto de salvaguardar a proteção à soberania e fronteiras dos Estados, no art. 41.1, estabeleceu-se que:

Nada do disposto na presente Declaração será interpretado no sentido de conferir a um Estado, povo, grupo ou pessoa qualquer direito de participar de uma atividade ou de realizar um ato contrário à Carta das 
Nações Unidas ou será entendido no sentido de autorizar ou de fomentar qualquer ação direcionada a desmembrar ou a reduzir, total ou parcialmente, a integridade territorial ou a unidade política de Estados soberanos e independentes. (ORGANIZAÇÃO NAÇÕES UNIDAS, 2008, p.3).

Então, o que se pode compreender como uma restrição ao direito à livre determinação é, de fato, a abertura para um direito especial para os povos indígenas, o qual deveria ser interpretado conforme à normatividade internacional sobre os direitos humanos.

O maior êxito desse diálogo intercultural foi mediado pelo respeito às diferenças epistemológicas do Estado e dos povos indígenas. Dessa maneira, descarta-se o modelo integracionista e o substitui por um modelo multicultural. A partir deste se reconhecem os indígenas como povo e sujeitos coletivos.

Portanto, deve-se compreender que, a partir dessas movimentações, as demandas do movimento indígena se fortalecem diante da esfera do direito internacional, uma vez que a autodeterminação dos povos indígenas constitui a base para os seus direitos coletivos. Evidencia-se, nessa esfera de direitos, a Declaração como um avanço significativo no combate à discriminação histórica. Em face disso, Aparicio Wilhelmi (2009, p. 19) afirma que somente com a garantia formal não se consegue atingir o núcleo da realidade social que se tenta afrontar, uma realidade ampla e heterogênea que precisa de respostas inclusivas e irrestritas, conforme observaremos nos demais tópicos.

\section{A construção da cidadania indígena na América Latina}

Aqui debateremos sobre a construção da cidadania indígena na América Latina a partir das movimentações constitucionais da década de 80 que, até hoje, é baseada nas demandas dos sujeitos sociais historicamente marginalizados, destacando-se o protagonismo indígena.

O conceito de cidadania já passou por diversas reformulações ao longo da história, desde a Grécia Antiga até a modernidade, quando recebe uma roupagem que, em sua maioria, permanece até os dias atuais. Nesse caminho histórico, passou a funcionar como um dos principais vetores do universalismo. Teoricamente, esse delineamento conceitual ficou conhecido através dos estudos do sociólogo Thomas Humphrey Marshall que estudou a cidadania da sociedade inglesa entre o século XIX e XX. Apesar da sua obra "Cidadania, Classe Social e Status" ser referência sobre a temática, o próprio autor explica que se trata de uma análise específica do processo histórico e social inglês, portanto, impassível de ser transplantado para outras realidades.

A partir da década de 80 , os debates sobre o conceito em questão avançaram pelo mundo. Já não era suficiente a concepção marshalliana de perfil democrática-liberal que se limitava a perceber o cidadão como um sujeito individual limitado a pleitear direitos perante o Estado. 0 
desafio é, portanto, compreender os saberes que foram ocultados e marginalizados no processo de colonização e vislumbrar possíveis alternativas ao paradigma hegemônico da modernidade na Europa, com o objetivo de intervir na realidade social.

O avanço da luta dos movimentos indígenas, assim como a instrumentalização de tratados internacionais de direitos humanos, conforme anteriormente explicitado - tais como a Convenção 169/OIT (1989) e Declaração das Nações Unidas sobre Povos Indígenas (2007) -, colaboraram para questionar o silêncio colonialista de algumas constituições frente à histórica exclusão do direito à diferença no conceito de cidadania. Na América Latina, os processos constituintes se apresentaram como espaços férteis para a incorporação de eixos epistemológicos provenientes dos saberes ancestrais, para a refundação de instituições tradicionais oriundas da colonização e para a criação de canais de participação popular nas estruturas do Estado.

Para a construção do conceito de cidadania, especificamente na seara do direito internacional, o fator de consciência indígena assume especial relevância no cenário da autodeterminação e da participação política com base no que é próprio e apropriado. Fortalece tal argumento a Convenção 169 da OIT, quando em seu artigo primeiro, inciso segundo, estabeleceu que a consciência da identidade indígena ou tribal é critério fundamental para a aplicação das disposições indigenistas. Portanto, compreende-se que esse reconhecimento do direito próprio dos povos indígenas acha sua gênese, inicialmente, nas disposições de caráter internacional.

Vale salientar, no entanto, que falar de cidadania indígena requer um certo zelo, uma vez que cada povo indígena latinoamericano é possuidor de características próprias que impedem a compreensão da cidadania indígena sob um olhar generalista.

Os povos indígenas possuem a capacidade de autodeterminar-se através de filosofias jurídicas próprias, ordens privativas próprias, instituições e juízes próprios e apropriados, competentes, independentes e autônomos em seus procedimentos e decisões. Um sistema com características próprias é um sistema que reconhece sua cultura, sua trajetória histórica, sua formação jurídica e política, além da sua espiritualidade e luta (ARIZA SANTAMARÍA, 2010, p.75).

Nesse sentido, entende-se como cultura própria a capacidade de resposta autônoma dos povos indígenas diante das agressões e dominações que sofreram, mas também como uma resposta de esperança, pois demonstram que são possuidores de algo próprio - sua cultura genuína - que precisa ser preservado.

Assim, o próprio e o apropriado estende possibilidades para que os povos indígenas determinem seus valores a partir de suas especificidades que os proporcionam o respeito pelas suas cosmovisões, desenvolvendo igualdade de direitos com as sociedades paralelas.

Com o fundamento jurídico na Convenção $169 / 89$, os povos indígenas com a consciência de sua identidade podem desejar assumir o controle de suas próprias instituições, de seus modos de vida e de seu 
desenvolvimento econômico, e manter e fortalecer suas identidades, línguas e religiões no âmbito dos estados em que vivem - o que permite considerar um exercício de cidadania levando em conta suas particularidades como povo.

Foi com a afirmação do pluralismo jurídico, da autodeterminação, da autonomia e da sustentabilidade que se encontrou na ideia de "cidadania multicultural" (SANTOS, 2003, p. 23) um espaço de disputa pelo fortalecimento do reconhecimento e da redistribuição; de crítica ao caráter etnocêntrico da cidadania liberal e soberania política estatal; de superação formal do princípio da tutela pela instrumentalização local, nacional e internacional da categoria "indígena" como identidade política simbólica, ajudando na construção do conceito de cidadania (LUCIANO, 2006, p. 31 ).

[...] os novos direitos de cidadania: novamente, exceto o Brasil, todos os demais países adotaram sistemas de direitos representados pelo pluralismo jurídico, consagrando direitos específicos para determinadas etnias e permitindo, inclusive, a criação e o reconhecimento de instâncias e instituições próprias desses segmentos, como a justiça indígena. Quanto aos tipos de direitos, observa-se a formação de dois grupos: o primeiro contém direitos concebidos a partir do aprimoramento ou da adequação de noções como liberdade e solidariedade, originárias do constitucionalismo europeu: o direito à autonomia étnica e o direito à diversidade cultural; o segundo é composto de direitos reconhecidos a partir da cultura dos países latino-americanos e expressam elementos das suas tradições históricas e culturais: o direito geral ao "bemviver" (suma qamaña na Bolívia e sumak kawsay no Equador), que envolve interesses ligados aos recursos naturais e energéticos, e os direitos da natureza, considerada como sujeito de direito no Equador. Em relação aos mecanismos de efetivação dos direitos de cidadania destacam-se: os canais de participação direta da sociedade civil e a criação de instâncias oficiais como conselhos cidadãos e tribunais de justiça indígena (BELLO, 2012, p. 121).

Dessa forma, pelo menos teoricamente na esfera internacional, a cidadania plena dos povos indígenas estaria resguardada pela reunião de garantias constitucionais de proteção e pela promoção da diversidade cultural, da autonomia política e do pluralismo jurídico. Essa linha de raciocínio é acompanhada por Santos (1988, p.75) quando trata o pluralismo como resultante de um processo de revolução social que gera ou produz um choque no direito tradicional.

A cidadania tem se convertido em um termo que atravessa a dimensão política, uma vez que é neste campo que a cidadania se concretiza. A cidadania é mais do que somente o reconhecimento de 
direitos: é a construção de cenários permanentes nos quais convivem os diferentes. Segundo Delgado (2007, p. 57), esta deve ser a redefinição do sentido de cidadania.

$\mathrm{Na}$ linha dos direitos já garantidos, o conceito de cidadania se expande e alcança modelos de participação democrática próprios, em correspondência com as práticas tradicionais dos povos indígenas. Assim, a noção de cidadania deve se aproximar da noção de minorias na América Latina. Dessa maneira, Raquel Coelho de Freitas preceitua:

Desse modo é que a cidadania pode ser compreendida de duas maneiras: primeiro, como a condição políticoinstitucional de toda pessoa, nacional ou não, a qual, uma vez abrigada por um Estado, possui legitimidade constitucional para demandar a efetivação de todos os direitos. Segundo, como a condição político-institucional que atribui a essa mesma pessoa a legitimidade de ter voz e direito de participar na organização democrática desse Estado (FREITAS, 2017, p.23)

Com o movimento constitucional latinoamericano, portanto, cidadanias adormecidas ao longo da história ganharam espaço. Para isso, os Estados Latinoamericanos precisaram assumir um papel político diferenciado, em que as minorias devem ser incluídas e respeitadas em seus modos de vida.

Assim, o embate entre as definições de cidadania ainda produz conflitos político-ideológicas entre os direitos individuais e direitos coletivos, a soberania da política estatal e a autonomia dos povos indígenas que, até hoje, continuam na luta por seu reconhecimento enquanto cidadão capaz de se autodeterminar.

O modelo de cidadania do novo constitucionalismo latinoamericano fomenta a cidadania ativa e o reconhecimento de direitos relativos às tradições ancestrais enquanto elementos constitutivos do cidadão. Dessa maneira, avança em relação aos parâmetros impostos pelo paradigma do universalismo, mas para transformar é preciso avançar em termos de resistência, enfrentamento e luta perante as estruturas capitalistas que persistem intocadas.

\section{A Autodeterminação como fundamento jurídico da prática de cidadania indígena}

O movimento constitucional na América Latina teve o potencial de fortalecer os direitos de autodeterminação e participação política dos povos indígenas, ratificando-os, dessa maneira, como sujeitos políticos atuantes na esfera pública. O desafio desse sistema de direito é garantir que o processo discursivo não seja distorcido por subjetividades de 
dominação e relações de poder, mas que promova práticas de autoformação dos sujeitos.

Nesse sentido, a autodeterminação tem o potencial jurídico para institucionalizar a prática da cidadania plena na esfera pública. Por isso, o sistema de direito indígena é fundamentado no princípio da autodeterminação como um instrumento de valor ético e político que permite aos sujeitos práticas de liberdade. No procedimento legislativo intercultural, portanto, este deve ser a base da instância de objetivos éticos e políticos.

Os povos indígenas participam da esfera pública sob diferentes perspectivas. De um lado, como sujeitos políticos que buscam relação com o Estado e, de outro, como contrapúblicos subalternos que tem logrado êxito em estremecer o marco liberal do qual se construía, a priori, seus direitos como povo (SANTOS, 2010, p.108).

Os sujeitos políticos, ao entrar na esfera pública, tem um maior respaldo sobre o direito de autodeterminação, uma vez que possuem ferramentas para se esquivar de relações de poder e estados de dominação, assim como para promover deliberações com um maior grau de legitimidade democrática.

Ainda segundo Boaventura de Sousa Santos (2009, p.52), a capacidade de cada transição de transformar a emancipação em regulação determinará a dialética que se espera entre as experiências e as expectativas sociais. Tal fenômeno é dinâmico e criativo, uma vez que não há um momento de conclusão definitivo e não repousa em sua natureza moderna.

Na prática da autodeterminação e do exercício pleno da cidadania contrastado com os sistemas estatais hegemônicos há uma dificuldade em definir a relação entre sociedade e cultura no desenvolvimento dos processos que ocorrem quando grupos com culturas diferentes e identidades diversas estão vinculadas por relações assimétricas de dominação e subordinação.

$\mathrm{Na}$ atualidade, as transformações políticas e institucionais da América Latina colocam em pauta a emergência de um novo estudo sobre o pluralismo jurídico no contexto do constitucionalismo latino-americano, que Boaventura denominou de novíssimo pluralismo jurídico.

O novíssimo pluralismo jurídico é dinamizado no âmbito do que denominei constitucionalismo transformador. A vontade constituinte das classes populares nas últimas décadas no continente latino-americano tem-se manifestado numa vasta mobilização social e política que configura um constitucionalismo a partir de baixo, protagonizado pelos excluídos e seus aliados, com o objetivo de expandir o campo do político para além do horizontal liberal, através de uma nova institucionalidade (plurinacionalidade), uma nova territorialidade (autonomias assimétricas), uma nova legalidade (pluralismo jurídico), um novo regime político (democracia intercultural) e novas subjetividades 
individuais e coletivas (indivíduos, comunidades, nações, povos, nacionalidades) (SANTOS, 2011, p.116).

Apesar da inclusão desses novos conceitos, percebe-se que seu mero caráter formal não é suficiente para a eficácia plena da cidadania indígena. Segundo Raquel Coelho de Freitas (2017, p. 27) "pode-se dizer que esse fortalecimento cidadão das minorias avançou até o momento em que a vontade constitucional correspondeu à ação governamental". Nesse sentido, observa-se como o direito dos povos indígenas - que eram e ainda são um grupo minoritário na América Latina, ficou vulnerável e dependente de instituições políticas estatais, embora tais garantias já estivessem formalizadas.

É por isso que se argumenta que a relação entre cidadania e política está intimamente interligada, tanto na teoria quando na prática, já que são tais instâncias que possibilitam a organização social e a defesa dos valores mais importantes dos grupos humanos com o fim de conversar uma ordem social. Assim, Rojas (2008, p.35) aduz que a cidadania é produto de uma construção social e, portanto, sujeita a mudanças na medida que depende da variação dos significados e imaginários locais e globais das comunidades.

Dentro do processo de construção de cidadãos e sujeitos políticos, a autodeterminação cumpre uma função essencial. O desafio é, portanto, além da garantia formal, a efetivação de uma cidadania que inclua o direito à diferença de uma forma que garanta ao povo indígena ser cidadão pleno sem deixar de ser parte de suas respectivas comunidades. Segundo Lévi-Strauss (1989, p.17) há uma tendência a subvalorização da cultura dos chamados "povos primitivos", pois atribuem a eles, exclusivamente, as necessidades orgânicas ou econômicas como força motriz de existência, desconsiderando suas necessidades espirituais e culturais.

Assim, uma cidadania apenas formalmente garantida e que não reflita o direito à diferença vai de encontro ao princípio da autodeterminação, uma vez que se viola sua existência plena, desconhecendo, portanto, sua cidadania.

\section{CONSIDERAÇÕES FINAIS}

Com o movimento constitucional na América Latina, cidadanias marginalizadas ao longo da história ganharam vez e voz. Para isso, o Estado precisou assumir um papel político e social diferenciado. Contudo, nem sempre a noção de cidadania assumida incluiu o reconhecimento do direito à diferença como legítima garantia de igualdade de condições pela equivalência, o que se mostrou ser um obstáculo na constituição de conjunturas sociais e políticas que permitam aos povos indígenas ser cidadãos plenos sem invisibilizar suas individualidades.

Observa-se, em um primeiro momento, que o princípio da autodeterminação é criação eminentemente do ramo do direito 
Espaço Ameríndio

internacional e que este se constituiu como um mecanismo de reforço para os direitos dos povos indígenas que buscam na reconfiguração do Estado na América Latina um marco do exercício dos seus direitos próprios.

Assim, o reconhecimento da autodeterminação na seara internacional deve ser valorado como um ataque frontal ao modelo monista dos Estados que vulnerabilizam os direitos dos povos indígenas na sua dimensão individual e coletiva. Dessa maneira, o princípio da autodeterminação, enquanto fenômeno jurídico internacional, consubstancia-se como uma forma de resistência na qual os povos indígenas acham espaço para a divulgação de seus discursos e que, concomitantemente, fundamenta o desenvolvimento dos seus planos de vida, instituições, sistemas e leis próprias.

A luta dos movimentos indígenas - assim como a instrumentalização de tratados internacionais de direitos humanos, tais como a Convenção 169/ OIT (1989) e Declaração das Nações Unidas sobre Povos Indígenas (2007) - colaborou com a garantia da cidadania aos povos indígenas. Não se pode, portanto, desprezar o potencial dos instrumentos jurídicos pós-coloniais ligados à afirmação da cidadania dos povos indígenas, uma vez que carregam força normativa para introduzir novos aportes às relações sociais multiculturais e institucionais, apesar do caráter liberal.

O modelo de cidadania do novo constitucionalismo latinoamericano, fomentado pelo princípio da autodeterminação dá base a uma cidadania ativa e ao reconhecimento de direitos relativos às tradições ancestrais enquanto elementos constitutivos do cidadão. Portanto, avança em relação aos parâmetros eurocêntricos liberais baseados na individualidade e na homogeneização das singularidades. No entanto, a mera formalidade de tais instrumentos não é suficiente para a concretização de uma cidadania plena, socialmente e culturalmente referenciada. Admite-se o simbolismo de tais instrumentos, mas os povos indígenas precisam de mais na luta para existir e resistir. 
Espaço Ameríndio

\section{Referências Bibliográficas}

ANAYA, James S. Los pueblos indígenas en el derecho internacional. Madrid: Trotta. 2005.

ANAYA, James S. Por qué no debería existir una declaración sobre derechos de los pueblos indígenas. In: ÁLVAREZ MOLINERO, Natalia; OLIVA MARTÍNEZ, J. Daniel; ZUÑIGA GARCÍA-FALCES, Nieves (eds). Declaración sobre los derechos de los pueblos indígenas. Hacia un mundo intercultural y sostenible. Madrid: Catarata, 2009.

APARICIO WILHELMI, Mauricio. Los pueblos indígenas y el derecho: los límites del reconocimiento jurídico de la multiculturalidad en América Latina. In: ÁLVAREZ MOLINERO, Natalia; OLIVA MARTÍNEZ, J. Daniel; ZUÑIGA GARCÍA-FALCES, Nieves (eds). Declaración sobre los derechos de los pueblos indígenas. Hacia un mundo intercultural y sostenible. Madrid, Catarata, 2009.

ARIZA SANTAMARÍA, Rosembert. Coordinación entre sistemas jurídicos y administración de justicia indígena en Colombia. Instituto Interamericano de Derechos Humanos. 2010.

BELLO, ENZO. A cidadania no constitucionalismo latino-americano. Caxias do Sul, EDUCS, 143 p, 2012.

BENAVIDES VANEGAS, Farid. Movimientos Indígenas y Estado Plurinacional en América Latina. In: Pensamiento Jurídico. Sobre lo público y lo privado en el derecho. No. 29 (septiembre - diciembre 2010). Bogotá: Facultad de Derecho, Ciencias Políticas y Sociales, Instituto Unidad de Investigaciones Socio Jurídicas Gerardo Molina, UNIJUS.

DELGADO, Ricardo. Los marcos de acción colectiva y sus implicaciones culturales en la construcción de ciudadanía. Universitas Humanística. 2007.

ORGANIZAÇÃO DAS NAÇÕES UNIDAS. Declaração das Nações Unidas sobre os direitos dos povos indígenas. (13 de setembro de 2017). Sessão plenária. Nova York, ONU, 2007.2 Disponível em: $<$ https://www.un.org/esa/socdev/unpfii/documents/DRIPS_pt.pdf $>$. Acesso em: $28 \mathrm{de}$ maio de 2019.

ROJAS, Cristina. La construcción de la ciudadanía en Colombia durante el gran siglo diecinueve 1810-1929. Paradigmas (29). 2008.

SANTOS, Boaventura de Sousa. O discurso e o poder; ensaio sobre a sociologia da retórica jurídica. Porto Alegre: Fabris, 1988.

SANTOS, Boaventura de Sousa. Reconhecer para libertar: os caminhos do cosmopolitismo multicultural. Rio de Janeiro:Civilização Brasileira. 2003 
Espaço Ameríndio

SANTOS, Boaventura de Sousa. Sociología Jurídica Crítica. Para un nuevo sentido común en el derecho. Bogotá: ILSA, 2009.

SANTOS, Boaventura de Sousa. Refundación del Estado de América Latina. Bogotá: Siglo del Hombre Editores, 2010. p. 108

SANTOS, Boaventura de Sousa. Para uma Revolucao Democrática de Justicia. Sao Paulo: Cortez, 2011.

LÉVI-STRAUSS, Claude. O pensamento selvagem. Tradução de Tânia Pellegrini. Campinas: Papirus, 1989.

LUCIANO, Gersem dos Santos. O índio brasileiro: o que você precisa saber sobre povos indígenas no Brasil de hoje. Brasília, MEC/SECAD; LACED/Museu Nacional. 2006 .

FREITAS, Raquel Coelho de. Minorias e Fortalecimento de Cidadanias na América Latina. In: SILVEIRA, B.; ARAÚJO, L.; ANDRADE, P. (Orgs.). Direito das Minorias no Novo Ciclo de Resistencias na América Latina. Curitiba: CRV, 2017, p.11-30. 